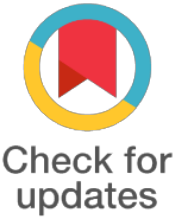

*For correspondence:

thanhthangphan@gmail.com

Competing interests: The authors declare that no competing interests exist.

Received: 2017-07-28

Accepted: 2017-08-18

Published: 2017-09-05

Copyright The Author(s) 2017. This article is published with open access by BioMedPress (BMP).

This article is distributed under the terms of the Creative Commons Attribution License (CC-BY 4.0) which permits any use, distribution, and reproduction in any medium, provided the original author(s) and the source are credited.

\section{Chromosomal abnormalities and treatment response in Multiple myeloma patients at Cho Ray hospital}

\author{
Thanh Thanh Suzanne, Oanh Hoang Le, Xinh Thi Phan, Tung Thanh Tran, \\ Thang Thanh Phan, Cuong Kim Nguyen, Hoa Hong Huynh
}

Cho Ray Hospital, Ho Chi Minh City

201B Nguyen Chi Thanh, Ward 12, Dist 5, Ho Chi Minh 7600oo, Vietnam

\section{Abstract}

Multiple myeloma (MM) is a malignant plasma cell, generating abnormal immunoglobulins in the blood and urin. From January 2012 to December 2014, we performed chromosome analysis and treatment for $44 \mathrm{MM}$ patients with the regimens containing Bortezomib (VD, VMP, VD plus autologus hematopoietic stem cell transplantation) at the Hematology department, Cho Ray hospital. The patient median of age was 64 year old, with the proportion of male/female was 0.83 . $\lg$ and $\lg A$ were two most common M-protein with accounting for $44.7 \%$ and $22.7 \%$, respectively. Patients were usually admitted to the hospital late in phase II and III of disease. 43 of $44 \mathrm{MM}$ patient haboring chromosomal abnormalities. Karyotyping analysis results showed that $3.7 \%$ cases with hypodiploidy and $14.8 \%$ cases hyperdiploidy. Translocation $\mathrm{t}(4 ; 14), \mathrm{t}(6 ; 14)$, $\mathrm{t}(11 ; 14)$ and $\mathrm{t}(14 ; 16)$ were found in $6.8 \%, 4.5 \%, 11.3 \%$ and $4.5 \%$ of cases, respectively. Del(13q) and del(17p) accounted for $31.8 \%$ and $29.5 \%$ of cases. High risk group was found in $40.9 \%$ of cases. Patients carrying the translocation $\mathrm{t}(4 ; 14)$ had the worse prognosis than other abnormalities with low response rate and overall survival, whereas higher rate of mortality. Results of our study showed that chromosomal abnormalities in MM are diversity and high percentage that affect the prognosis. Therefore, we need to indentify chromosomal abnormalities before treatment to select appropriate therapy regiments.

\section{Keywords}

Multiple myeloma, Karyotyping, Chromosomal abnormalities Funding

\section{References}

1. Avet-Loiseau H, Attal M, Moreau P, Charbonnel C, et al. Genetic abnormalities and survival in multiple myeloma: the experience of the Intergroupe Francophone du Myelome. Blood 2007; 109(8):3489-95.

2. Fonseca R, Blood EA, Oken MM, et al. Myeloma and the $\mathrm{t}(11 ; 14)$ (q13;q32); evidence for a biologically defined unique subset of patients. Blood 2002; 99(10):3735-41.

3. Greipp PR, San Miguel J, Durie BG, et al. International staging system for multiple myeloma. J Clin Oncol 2005; 23(15):3412-20.

4. Kyle RA, Gertz MA, Witzig TE, et al. Review of 1027 patients with newly diagnosed multiple myeloma. Myo Clin Proc 2003; 78(1):21-33. 